\title{
Perancangan Network Monitoring Tools Menggunakan Autonomous Agent Java
}

\author{
Khurniawan E S ${ }^{\mathrm{a} 1}$, L.Ahmad S. Irfan Aa2 ,I B K Widiartha ${ }^{\mathrm{b} 3}$ \\ aJurusan Teknik Elektro Fakultas Teknik Universitas Mataram \\ JIn. Majapahit No.62 Mataram Nusa Tenggara Barat Kode Pos: 83125 \\ 1,2Telp. (0370) 636087; 636126; ext 128 Fax (0370) 636087 \\ bProgram Studi Teknik Informatika Universitas Mataram \\ JIn. Majapahit No.62 Mataram Nusa Tenggara Barat Kode Pos: 83125 \\ ${ }^{3}$ Telp. (0370) 636087; 636126; ext 128 Fax (0370) 636087
}

\begin{abstract}
Abstrak
Tugas pengelolaan jaringan yang dilakukan administrator jaringan diantaranya yaitu pengumpulan informasi resource jaringan yang tersedia. Teknologi SNMP (Simple Network Management Protocol) memberikan fleksibilitas bagi administrator jaringan dalam mengatur network secara keseluruhan dari satu lokasi. Aplikasi Network Monitoring Tools berbasis Agent JAVA terdiri dari Master agent yang bertugas untuk melakukan management Request agent serta akses database. Request agent yang bertugas untuk melakukan pemantauan server yang mengimplementasi library SNMP4j dengan sistem multi-agent. Disisi interface, aplikasi Network Monitoring Tools menggunakan media web sebagai interface administrator sehingga dapat digunakan darimana saja dan kapan saja. Hasil dari penelitian ini memperlihatkan bahwa aplikasi yang dibuat bekerja sebagai Network Monitoring Tools mampu bekerja dengan persen error pada kisaran 0-18\%. Selain itu Aplikasi ini menghasilkan tren pembacaan data server lebih stabil dan cepat dibandingkan dengan aplikasi Cacti. Hal ini didukung oleh kemampuan Request Agent yang mampu merespon tingkat beban kerja server yang di pantau.
\end{abstract}

Kata kunci : Agent, JAVA, SNMP, Cacti, Network monitoring.

\begin{abstract}
Network management tasks are performed by the Network Administrator such as gathering available network resources information. The SNMP (Simple Network Management Protocol) Technology provides flexibility for network administrators in managing the overall network from a single location. Agent based Network Monitoring Tools JAVA Application consists of Master agent whose job is to perform as well as the management agent Request and database access. The Request agent in charge for monitoring servers that implement SNMP4j library with multi agent systems. For interface, Network Monitoring Tools application using web media as an administrator interface that can be used from anywhere and at anytime. The results of this study showed that the application as a Network Monitoring Tools are able to work with the percent error in the range of 0-18\%. Besides these applications generate trend data readout server more stable and faster than the application Cacti do. This is supported by the ability of the Request Agent to respond the level of server workloads
\end{abstract}

Keywords : Agent, JAVA, SNMP, Cacti, Network monitoring.

\section{Pendahuluan}

Tugas pengelolaan jaringan yang dilakukan administrator jaringan memiliki sejumlah kesulitan, diantaranya yaitu pengumpulan informasi resource jaringan yang tersedia serta melakukan pemantauan terhadap server dan router yang beroperasi pada jaringan. Manajemen sistem jaringan komputer berbasiskan pada teknologi SNMP (Simple Network Management Protocol)

yang memberikan fleksibilitas bagi administrator jaringan dalam mengatur network secara keseluruhan dari satu lokasi [1]. Banyak aplikasi $3^{\text {rd }}$ party seperti cacti, MRTG, monit, munin, 
nagios, zenos dan zabix yang menyediakan banyak fitur dalam manajemen sistem jaringan komputer menggunakan protokol SNM, dan diakses melalui web browser [2]. Namun aplikasiaplikasi tersebut cukup sulit dikustomisasi menyesuaikan dengan kebutuhan instansi pengguna. Dibutuhkan sebuah aplikasi mandiri yang sederhana agar mudah disesuaikan dengan kebutuhan dan memiliki fitur-fitur monitoring seperti pada aplikasi $3^{\text {rd }}$ party pada umumnya. Untuk menjawab permasalahan tersebut maka dibuatlah sebuah aplikasi Network Monitoring Tools (NMT) berbasis Agent JAVA. Agent JAVA mampu bekerja secara berulang-ulang (Autonomous) dan merespon sesuai dengan parameter yang diterima. Penggunaan Agent JAVA sebagai pemantau server yang mampu merespon kondisi pembebanan server dalam bentuk interval pengambilan datanya (request scheduling) diharapkan dapat menjadi solusi untuk aplikasi mandiri Network Monitoring Tools pada jaringan Fakultas Teknik Universitas Mataram.

\section{Landasan Teori}

\subsection{SNMP}

Secara sederhana, SNMP merupakan sebuah protokol yang didesain untuk memberikan kemampuan kepada pemakai untuk mengelola jaringan komputernya dari jarah jauh atau remote[3]. Adanya SNMP memungkinkan manajemen jaringan yang tersentralisasi, kuat, dan kompatibel pada semua platform. Tujuan utama dari protokol SNMP hanya pada satu tujuan yaitu melakukan remote manajemen dari peralatan [4]. Sebuah jaringan yang dapat di-manage menggunakan SNMP pada dasarnya memiliki tiga komponen, yaitu Managed Device, Agent SNMP, dan Network-management System [4]. Sebuah managed device adalah sebuah node (dapat berupa server, switch, router) di jaringan yang berisi Agent SNMP yang berada di jaringan yang dapat di manage. Agent SNMP adalah sebuah modul software network management yang berada di dalam managed device. Agent ini mengetahui tentang informasi manajemen dan dalam menterjemahkan ke informasi yang kompatibel dengan SNMP. Pada sistem operasi linux telah disediakan aplikasi snmpd sebagai agent SNMP. Aplikasi NMS menjalankan aplikasi yang dapat memonitor dan mengontrol managed device. NMS memberikan resource memory dan prosesor yang dibutuhkan untuk manajemen network.

\subsection{Agent Java}

Software Agent (selanjutnya di sebut Agent saja) adalah entitas perangkat lunak yang didedikasikan untuk tujuan tertentu. Agent bisa memiliki ide sendiri mengenai bagaimana menyelesaikan suatu pekerjaan tertentu atau agenda tersendiri. Karakteristik dari Agent [5]:

a. Autonomy: komputer umumnya hanya berespon pada manipulasi langsung. Kontras dengan Agent perangkat lunak yang mengamati lingkungannya dan bisa melakukan tindakan otonom.

b. Reaktif: suatu software Agent berespon dalam waktu yang bermacam-macam untuk merubah dalam lingkungannya

c. Goal driven: suatu Agent bisa menerima Request tingkat tinggi yang menentukan tujuan dari user manusia (atau Agent lainnya) dan memutuskan dimana dan bagaimana untuk menjawab Request tersebut.

Agent yang tidak berpindah ke host lain disebut stationary Agent. Multi agent system adalah sebuah system yang memungkinkan sejumlah agent (multi agent) bekerja sama untuk menyelesaikan suatu masalah yang tidak dapat dikerjakan oleh individu agent [5]. Pada multi agent system, setiap agent bekerja secara multithreading diatas runtime JAVA sehingga memberikan impresi bahwa agent mampu bekerja secara paralel independent.

\subsection{JADE}

JADE (Java Agent DEvelopment Framework) merupakan sebuah kerangka kerja perangkat lunak yang diimplementasikan sepenuhnya dalam bahasa Java [6]. JADE memudahkan implementasi dari Multi-Agent sistem (MAS) melalui middleware yang bekerja sesuai spesifikasi FIPA (Foundation for Intelligent Physical Agent). Karena sepenuhnya diimplementasikan dalam bahasa pemrograman Java, maka JADE juga mendapatkan seluruh keuntungan dari bahasa pemrograman tersebut, termasuk ketidak-tergantungan pada arsitektur platform. Agent platform 
pada JADE dapat didistribusikan di beberapa mesin yang berbeda, dan tidak perlu menggunakan sistem operasi yang sama.

\section{Metode Penelitian}

\subsection{Analisis Kebutuhan}

Sistem monitoring yang saat ini berjalan banyak menggunakan tools-tools buatan luar negeri yang memanfaatkan protokol SNMP sebagai media monitoring pada suatu server. Aplikasi yang baru tetap menggunakan protokol SNMP sebagai media monitoring agar tidak terjadi perubahan langsung pada konfigurasi server dengan adanya penggantian aplikasi monitoring. Network Monitoring Tools yang akan dibangun adalah pemanfaatan dari teknologi Agent JAVA, yang mana untuk proses monitoring dalam satu server ditangani oleh sebuah Agent. Semakin banyak host yang perlu dipantau maka Agent yang diperlukan juga akan semakin banyak dan membutuhkan spesifikasi komputer yang cukup tinggi. Interval Request Data akan diatur oleh Agent dengan memantau tingkatan traffic jaringan dan beban kerja host. Ini artinya Agent yang akan melakukan Request data akan secara bergiliran melakukan pengambilan data, sehingga traffic jaringan lebih stabil tanpa mengurangi performa aplikasi monitoring.

\subsection{Perancangan Sistem}

Perangkat lunak yang akan dibangun adalah sebuah tools untuk memantau jaringan atau Network Monitoring Tools. Pemantauan jaringan dilakukan dengan cara memanfaatkan protokol SNMP untuk mengakses MIB (Management Information Bases) tiap host dan mendapatkan data sesuai OID (Object ID) yang dikirimkan oleh aplikasi daemon snmpd. Proses permintaan data resource menggunakan library JAVA SNMP4j dan menghasilkan data set dari resource server yang dipantau. Data set ini kemudian di simpan kedalam database dan ditampilkan pada aplikasi web yang di akses oleh client secara realtime sesuai data yang diterima.

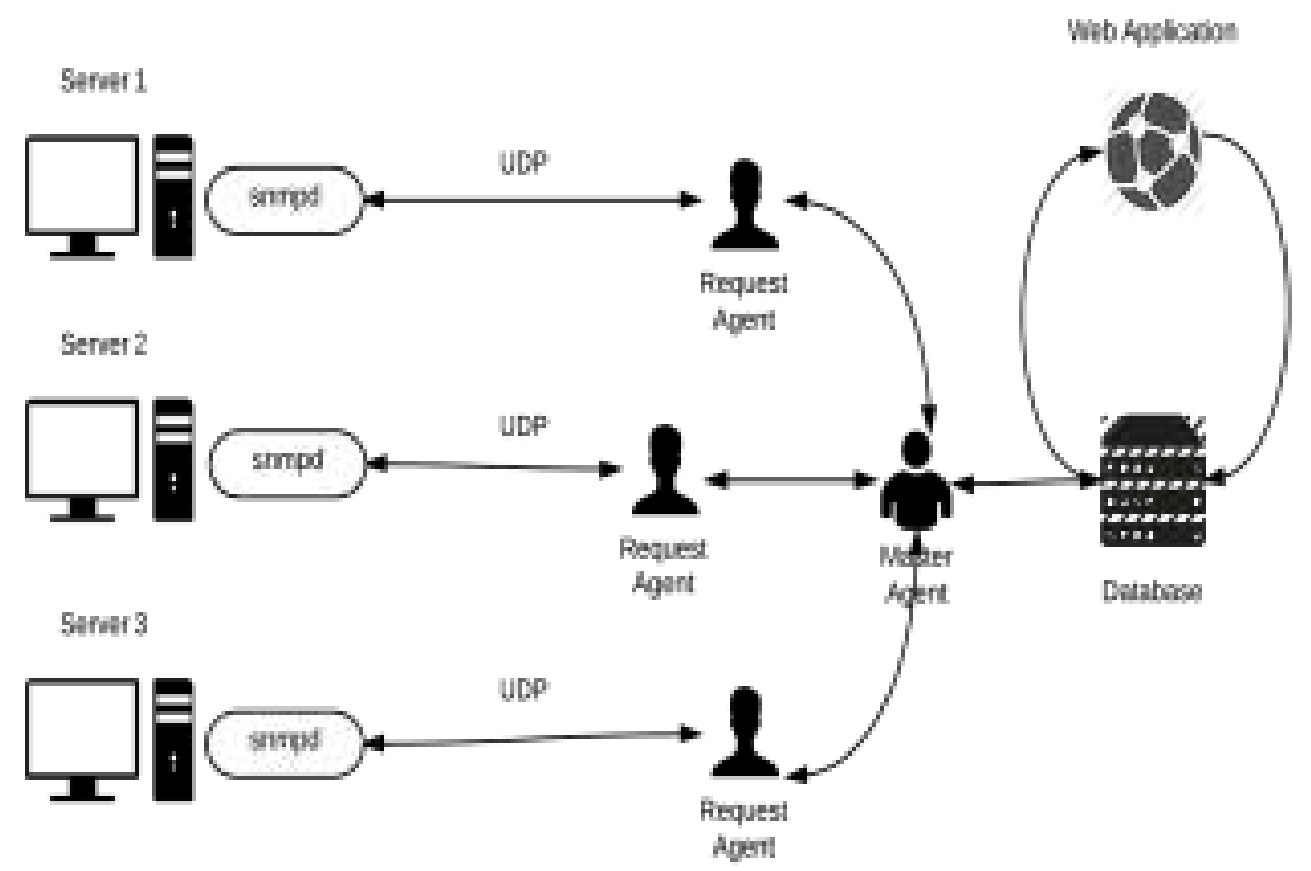

Gambar 1. Ilustrasi Sistem Monitoring 
Berikut penjelasan alur proses monitoring jaringan :

a. Dengan menggunakan interface web, admin mendaftarkan semua server yang ingin dipantau kedalam Sistem

b. Perangkat lunak yang akan dibangun adalah sebuah tools untuk memantau jaringan atau Network Monitoring Tools. Pemantauan jaringan dilakukan dengan cara memanfaatkan protokol SNMP untuk mengakses MIB (Management Information Bases) dan disimpan pada database komputer monitoring. Pendaftaran terdiri dari IP address, port SNMP, dan community Key untuk mengakses snmpd pada server tersebut.

c. Aplikasi mencetak 2 jenis Agent yaitu Master Agent dan Request Agent. Master Agent adalah Agent yang bertugas untuk mencetak Request Agent sesuai dengan data host yang terdapat pada database, menerima data resource jaringan dari Request Agent dan meng-entry data tersebut ke database aplikasi. Request Agent adalah Agent yang akan melakukan Request data ke server yang ingin dipantau, melakukan pengolahan data mengirimkan hasilnya ke Master Agent.

d. Request Agent akan melakukan Request resource data yang terdiri dari bandwidth traffic, memory usage, CPU usage, dan disk usage ke server secara bergantian dengan interval waktu berdasarkan tingkat beban kerja dan traffic server. Interval waktu ini diperoleh dari kategori tingkat traffic data dan penggunaan CPU serta RAM.

e. Pada Web Application, sistem akan mengakses database secara realtime untuk mendapatkan informasi resource jaringan yang telah dikumpulkan oleh Master Agent.

\subsection{Programming}

Berikut beberapa prosedur yang digunakan dalam pembuatan program Network Monitoring JAVA :

a. Prosedur utilitas sistem

Prosedur ini berfungsi sebagai pendukung aplikasi Agent. Terdiri dari koneksi database, akses file konfigurasi dan penyedia logging error.

b. Prosedur Agent

Prosedur ini berfungsi sebagai prosedur utama agent. Pada prosedur agent terdiri dari

2 class yaitu class master agent dan class request agent.

c. Prosedur komunikasi Agent

Prosedur ini digunakan oleh Agent untuk berkomunikasi dan bertukar data antar Agent.

d. Prosedur pemantauan server

Prosedur ini digunakan oleh Agent untuk melakukan pemantauan server. Tediri dari pembentukan koneksi protocol UDP, pengaksesan protocol SNMP dan proses-proses pengolahan data yang diterima oleh Agent

\subsection{Pengujian}

Dalam pembuatan sistem, pengujian ditujukan untuk mengetahui kinerja sistem dalam melakukan proses pengumpulan data resource server. Tahapan pengujian yang dilakukan antara lain :

a. Pengujian pembacaan data protokol SNMP

Protokol SNMP diakses dengan memanfaatkan library tambahan SNMP4j dengan output berupa sebuah set data yang siap disimpan ke database. Pengujian dilakukan dengan memeriksa apakah library tersebut dapat memberikan respon output set data sesuai input OIDnya.

b. Pengujian perbandingan hasil pemantauan dengan aplikasi Cacti

Pengujian perbandingan hasil pemantauan dengan aplikasi Cacti berfungsi untuk mengetahui kinerja Network Monitoring Tools dibandingkan dengan kinerja cacti sebagai aplikasi yang telah banyak digunakan. 


\section{Hasil dan Pembahasan}

\subsection{Pengujian pembacaan data protokol SNMP}

Perbandingan memanfaatkan aplikasi top, bmon dan df sebagai referensi daa real dihasilkan data sebagai berikut :

Tabel 1. Perbandingan hasil pemantauan system

\begin{tabular}{lcccc}
\hline No & Item & Data real & Data pemantauan & \%error \\
\hline 1 & Processor & $78.7 \%$ & $78 \%$ & $3.74 \%$ \\
2 & RAM Used & $363 \mathrm{MB}$ & $321 \mathrm{MB}$ & $11.57 \%$ \\
3 & Traffic IN & $17 \mathrm{KBps}$ & $14 \mathrm{KBps}$ & $17.64 \%$ \\
4 & Traffic OUT & $47 \mathrm{KBps}$ & $42 \mathrm{KBps}$ & $10.63 \%$ \\
5 & & & $0 \%$ \\
6 & Disk Used & $10.3 \mathrm{~GB}$ & $10.3 \mathrm{~GB}$ & $0 \%$ \\
\hline
\end{tabular}

Dari tabel diatas terdapat besaran error antara pembacaan secara realtime dengan hasil pemantauan. Faktor utama yang menyebabkan perbedaan hasil pemantauan antara aplikasi $d f$, bmon dan top dengan aplikasi Network monitoring tools memiliki delay waktu pengambilan. Ketiga aplikasi tersebut memberikan informasi secara real time, sedangkan aplikasi Network Monitoring Tools mengambil data dengan kecepatan berubah-ubah dengan nilai maksimum 20 detik sekali. Hal ini dikarenakan MIB pada SNMP daemon hanya mengupdate databasenya dengan rate berkisar 15-20 detik. Apabila data diambil kurang dari rate tersebut maka data yang didapatkan akan selalu sama. Faktor lainnya yang mempengaruhi perbedaan hasil pemantauan adalah sistem pembulatan besaran yang didapat.

\subsection{Pengujian perbandingan hasil pemantauan dengan aplikasi Cacti}

Pada pengujian ini hasil pemantauan aplikasi WLTI Network Monitoring Tools akan dibandingkan dengan hasil pemantauan aplikasi Cacti. Pengujian ini bertujuan untuk mengetahui perbandingan kinerja aplikasi WLTI Network Monitoring Tools dengan aplikasi yang telah digunakan secara umum. Berikut perbandingan data hasil pemantauan server yang diambil secara bersamaan dengan kondisi server idle: 


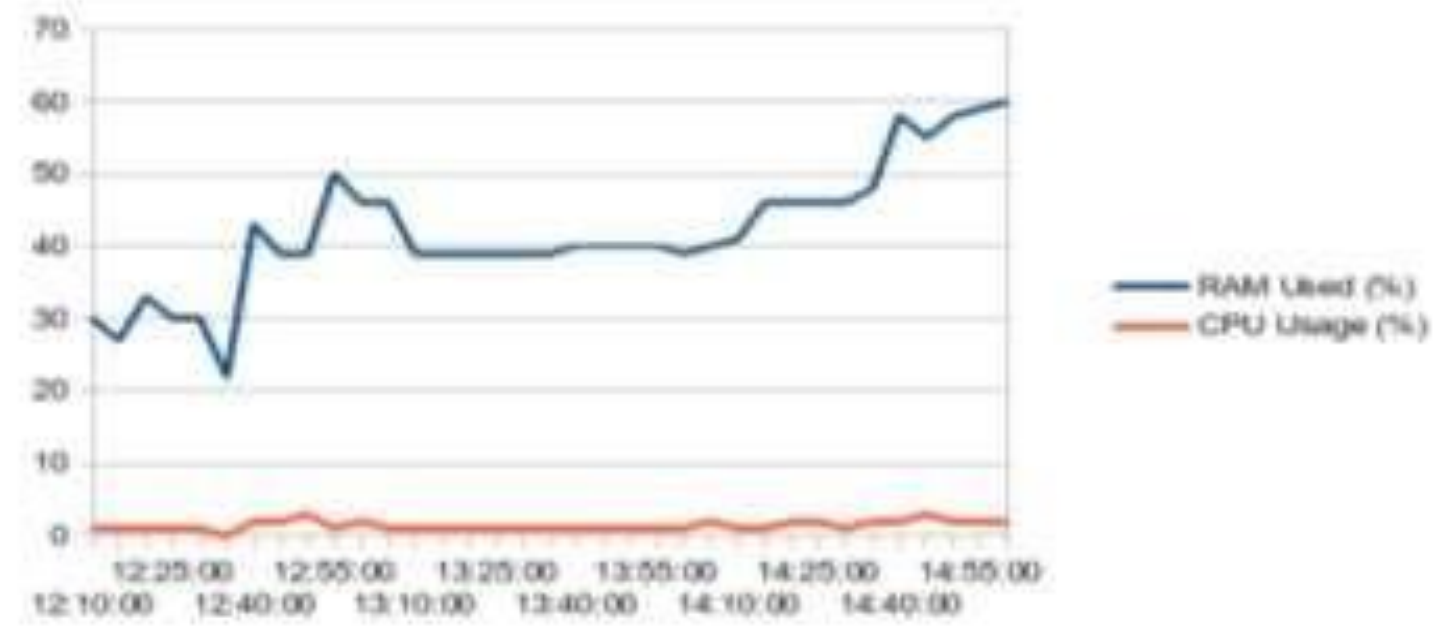

Gambar 2. Grafik data hasil pemantauan RAM dan CPU server oleh cacti

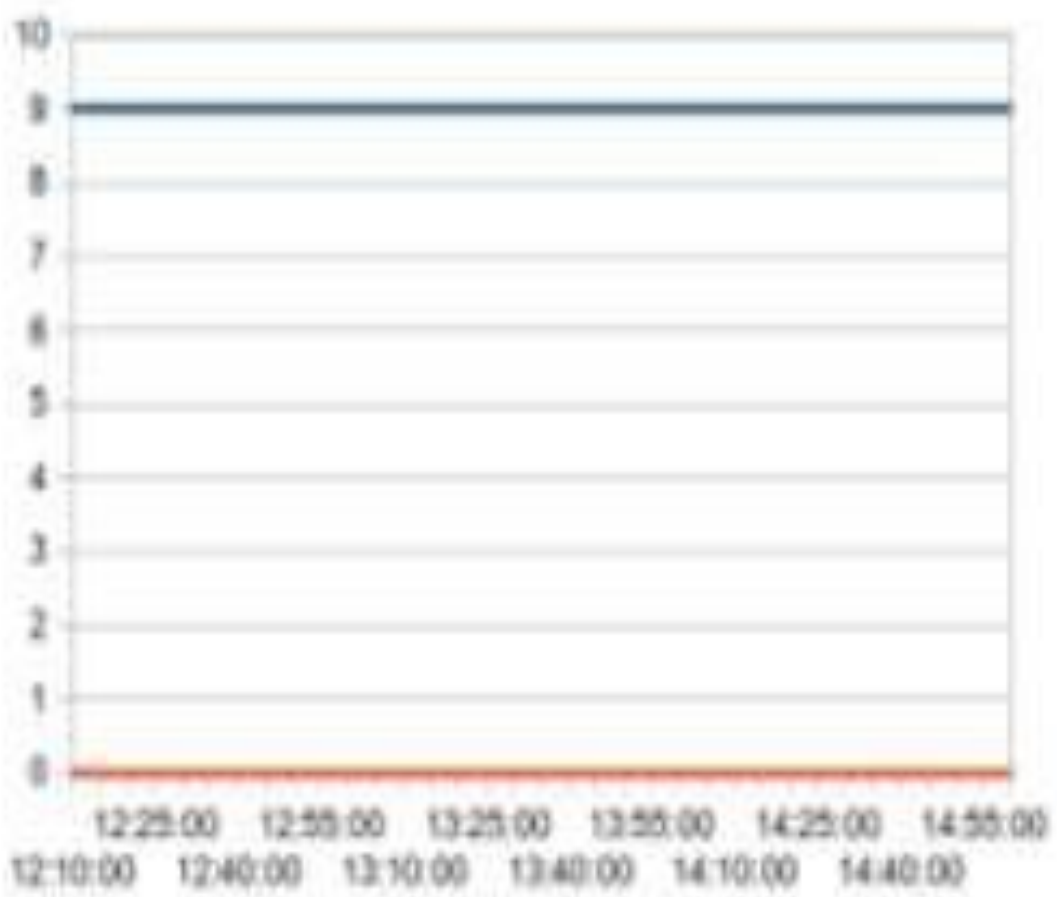

Gambar 3. Grafik data hasil pemantauan RAM dan CPU server oleh WLTI NMT

Dari kedua perbandingan diatas keanehan muncul pada data hasil pemantauan cacti. Secara logis kondisi server yang idle memiliki besaran penggunaan RAM dan CPU berada pada level terendah dan stabil (tidak berubah-ubah). Sedangkan pada grafik hasil pemantauan cacti (gambar 2) dapat dilihat terdapat fluktuasi penggunaan resource server yang terus meningkat. Sedangkan pada aplikasi WLTI penggunaan RAM dan CPU stabil dilevel $9 \%$ dan $0 \%$. Hal ini logis mengingat kondisi server yang idle dan dapat dicocokkan dengan aplikasi monitoring bawaan linux seperti top. Diluar dari kompleksitas, fitur-fitur dan cakupan entitas jaringan yang mampu dipantau oleh cacti, dari kedua grafik perbandingan diatas dapat disimpulkan bahwa aplikasi WLTI NMT memiliki akurasi pemantauan yang lebih baik dari cacti. Selain itu aplikasi 
WLTI NMT mampu melakukan pengambilan data dengan interval hingga 20 detik sedangkan cacti hanya menyediakan interval di 5 menit.

\section{Kesimpulan}

Dari penelitian yang telah dilakukan, dapat ditarik kesimpulan sebagai berikut ; Persentase error pembacaan data oleh aplikasi sebesar 3.74\% untuk CPU Usage, $11.57 \%$ untuk RAM Usage, 17.64\% untuk Traffic IN dan 10.63\% untuk Traffic Out. Hal ini dipengaruhi oleh interval pengambilan data dan sistem pembulatan besaran data. Sedangkan persentase error pembacaan data untuk disk usage dan disk free sebesar $0 \%$. Hasil pengujian perbandingan antara WLTI NMT dengan Cacti menunjukkan bahwa pada kondisi server istirahat (idle) data hasil pembacaan oleh Cacti menampilkan grafik penggunaan RAM yang cenderung naik dan grafik penggunaan CPU yang konstan. Sedangkan data hasil pembacaan oleh WLTI NMT menampilkan grafik penggunaan RAM dan CPU yang konstan. Hal ini berarti aplikasi WLTI Network Monitoring Tools lebih akurat dibanding Cacti. Pengambilan data oleh aplikasi Network Monitoring Tools yang mampu bekerja dengan interval maksimum sebesar 20 detik sekali, sedangkan Cacti hanya mampu bekerja dengan interval sebesar 5 menit sekali. Hal ini berarti bahwa WLTI Network Monitoring Tools mampu menyajikan data lebih akurat. Agent JAVA berbasis JADE dapat diimplementasikan sebagai pemantau server dengan memanfaatkan library SNMP4j sebagai penyedia layanan akses ke protokol SNMP.

\section{Daftar Pustaka}

[1] H. Sajati, "Memonitor Server Dengan Cacti," Academia.edu.

[2] "Pengawasan Jaringan Berbasis Web." 2007. [Online]. Available: ftp://ftp.gunadarma.ac.id/linux/magazine/infolinux/2007/InfoLINUX_07-2007/38-

41_Alternatif_07.pdf. [Accessed: 03-May-2016].

[3] A. M. Shiddiqi and A. P. Nugraha, "Sistem Monitoring Jaringan Dengan Protokol Snmp." 2011.

[4] Cisco, "Simple Network Management Protocol." pp. 1-8, 2013.

[5] D. B. Lange and M. Oshima, "Programming and deploying Java mobile agents with Aglets," in IBM Japan, 1998, p. 225.

[6] F. Bellifemine, G. Caire, and D. Greenwood, Developing multi agent systems with jade. London: John Wiley \& Sons. Ltd, 2004. 